\title{
La atenuación lingüística en el texto dramático: el guion de Confesión a Laurd"
}

\author{
VÍCTOR JULIÁN VALLEJO ZAPATA** \\ FRANCISCO OCTAVIO ZULUAGA GÓMEZ"**
}

Recepción: 28 de febrero de 2018

Aprobación: 4 de octubre de 2018

Forma de citar este artículo: Vallejo, V. J. \& Zuluaga, F. 0. (2019). La atenuación lingüística en el texto dramático: el guion de Confesión a Laura. Cuadernos de Lingüística Hispánica, (33), 125-149.

10.19053/0121053X.n33.2019.7788

* Artículo de investigación. Este artículo es producto del seminario últimas tendencias en la investigación de los fenómenos pragmáticos y la Lingüística de Corpus, dictado por la doctora Marta Albelda en el marco del Doctorado en Lingüística de la Universidad de Antioquia, marzo de 2016. Agradecemos su acompañamiento en la preparación de este artículo.

** Magíster en Lingüística, Universidad de Antioquia. Docente de cátedra, Universidad de Antioquia. Correo electrónico: victor. vallejo@udea.edu.co (iD https://orcid.org/0000-0002-5965-4880

*** Doctor en Lingüística, Universidad de Ámsterdam. Docente vinculado, Universidad de Antioquia. Correo electrónico: francisco. zuluaga@udea.edu.co Đ https://orcid.org/0000-0001-8379-9804 


\title{
Resumen
}

El presente artículo de investigación describe el fenómeno pragmalingüístico en el guion de la película Confesión a Laura (Cardona, 2010), entendiendo este como un tipo de texto dramático, cercano aunque diferente al texto teatral. Para la codificación de los datos, se usa la ficha de atenuación desarrollada por el grupo Val.Es.Co (2013) con algunas modificaciones derivadas de la tipología textual analizada. Se emplean estadísticos descriptivos para el análisis de los datos y se señalan elementos relevantes para la comprensión del corpus. Se concluye que el método diseñado por Val.Es.Co es pertinente para discursos de ficción y se dan recomendaciones de trabajo futuro.

Palabras clave: atenuación, guion cinematográfico, variables sociolingüísticas, Confesión a Laura.

\section{The Linguistic Attenuation in the Dramatic Text: The Script of Confessing to Laura}

\begin{abstract}
This research article describes the pragmalinguistic phenomena in the script of the film Confession to Laura (Cardona, 2010), understanding it as a dramatic text type, close although different from the theatrical text. For coding the data, the attenuation sheet developed by the group Val.Es.Co (2013) is used with some modifications derived from the textual typology analyzed. Descriptive statistics are used to analyze the data and relevant elements are pointed out for understanding the corpus. It is concluded that the method designed by Val.Es.Co is relevant to fictional discourses and recommendations for future work are given.
\end{abstract}

Keywords: attenuation, film script, sociolinguistic variables, Confessing a Laura. 


\section{L'atténuation linguistique dans le texte dramatique : le scénario de Confession à Laura}

\section{Résumé}

Cet article de recherche décrit le phénomène pragmalinguistique dans le scénario du film Confession à Laura (Cardona, 2010), en le comprenant comme un texte dramatique, proche bien que différent, du texte théâtral. Pour le codage de données, on utilise une fiche d'atténuation développée par le groupe Val.Es.Co (Valence Espagnol Colloquial, 2013) avec quelques modifications dérivées de la typologie textuelle analysée. On emploie des statistiques descriptifs pour l'analyse des données et on signale des éléments pertinents pour la compréhension du corpus. On conclut que la méthode créée par Val. Es.Co est pertinente pour des discours de fiction et on fait des recommandations pour un futur travail.

Mots clés : atténuation, scénario cinématographique, variables sociolinguistiques, Confession à Laura.

\section{A atenuação linguística no texto dramático: o roteiro de Confissão para Laura}

\section{Resumo}

0 presente artigo de pesquisa descreve 0 fenômeno pragmalinguístico no roteiro do filme Confesión a Laura (Cardona, 2010), entendendo este como um tipo dramático de texto, próximo, embora diferente do texto teatral. Para codificação dos dados, a folha de atenuação desenvolvida pelo grupo Val.Es.Co (2013) é utilizada com algumas modificações derivadas da tipologia textual analisada. Estatísticas descritivas são utilizadas para analisar os dados e elementos relevantes são apontados para a compreensão do corpus. Conclui-se que o método desenhado por Val.Es.Co é relevante para os discursos fictícios e recomendações para trabalhos futuros são dadas.

Palavras-chave: atenuação, roteiro cinematográfico, variáveis sociolinguísticas, Confissão a Laura. 


\section{Introducción}

El presente artículo constituye una descripción de los tipos de atenuación presentes en el intercambio comunicativo de Confesión a Laura, tomado desde el texto específico del guion cinematográfico (Cardona, 2010). Se aplican los parámetros de la ficha metodológica para el análisis de la atenuación propuesta por el grupo Val.Es.Co (Albelda, Briz, Cestero, Kotwica \& Villalba, 2014; Grupo Val.Es.Co, 2013, 2014), con algunas modificaciones mínimas.

La atenuación como objeto de estudio cuenta con la estrategia metodológica de la ficha de análisis referida; por supuesto, en tanto el grupo Val.Es.Co se focaliza en español coloquial, esta ha sido aplicada mayoritariamente a corpus de conversaciones coloquiales y reales, con alguna excepción: Villalba (2015) aplica la ficha a los juicios penales orales, con lo que amplía el campo de acción de dicha estrategia.

Por otro lado, este artículo retoma indagaciones previas de fenómenos pragmáticos en corpus literarios, donde hemos establecido su valor al reflejar los usos de una época y contexto (Haverkate, 2002; Vallejo, 2012). La presente investigación continúa (y sustenta) esa perspectiva: sin pretender reemplazar el análisis de corpus de conversaciones reales, busca complementarla; además brinda evidencias para los análisis semióticos de la literatura, el guion cinematográfico y el cine.

En último término, enunciaremos brevemente las relaciones entre el guion (Cardona, 2010) y la película propiamente dicha (Cardona \& Osorio, 1990). La comparación formal entre ambos géneros discursivos quedará planteada como una posibilidad de investigación promisoria tanto para la pragmática como para la estética.

\section{Confesión a Laura}

Con el prestigio de ser una de las películas más premiadas del cine colombiano ${ }^{1}$, Confesión a Laura (Cardona \& Osorio, 1990) resalta como una cinta bellísima y brillante. Se trata de un relato intimista, enmarcado en "el Bogotazo", uno de los episodios más trágicos de la historia de Colombia, consistente en violentísimos desmanes y protestas acaecidas en la capital del país y algunas provincias, como consecuencia del asesinato del caudillo liberal Jorge Eliecer Gaitán, el 9 de abril de 1948, con un número de víctimas no confirmado que ascendería a varios miles.

1 La información completa de producción y reconocimientos se puede consultar en http:// www.proimagenescolombia.com/secciones/cine_colombiano/peliculas_colombianas/pelicula_ plantilla.php?id_pelicula=1533 
Al día siguiente de "el Bogotazo", Josefina (mandona ama de casa que ronda los 40 años) ordena a su esposo Santiago (apocado empleado del gobierno, en los 50) que le lleve la torta de cumpleaños a Laura, su vecina de enfrente (profesora de colegio, también por los 40). Él se resiste, pues las calles aún sufren los desmanes, pero se siente intimidado por su esposa y termina por ceder. Al llegar al apartamento de Laura se reactiva la violencia y se ven obligados a permanecer encerrados. A medida que avanza el día se van revelando detalles de los dos cautivos, particularmente su soledad y frustración por aquello que no lograron ser o conseguir, mientras la subcultura de distanciamiento típica de la capital va cediendo ante el descubrimiento mutuo.

Entre Santiago y Laura está la curiosidad, que en ella produce entusiasmo y admiración por Santiago, pero pudor y vergüenza por lo que Santiago descubre. La misma curiosidad produce en Santiago complicidad y serenidad hacia Laura y, al tiempo, frustración por lo que es y orgullo por lo que quiere ser. (Ceballos, 2006, p. 182)

Entretanto, Josefina los observa desde su apartamento, que está al mismo nivel que el de Laura. Alexandra Cardona, la guionista, sintetiza la carga dramática de la obra en la siguiente imagen:

[...] desde la ventana de un apartamento, desde la que se puede ver la del frente, vemos a dos personas sentadas en los extremos de un sofá. Pero cuando hacemos el contraplano, cuando vemos desde el interior del apartamento, descubrimos que del muro para abajo realmente tienen un juego de coquetería, se están tocando las manos, los pies. ¿Quiénes son estos personajes y por qué se acarician así? (2010, pp. 123-124)

Podemos coincidir con las críticas especializadas que, en distintas ocasiones, la han calificado como la mejor y más grande historia de amor del cine colombiano (Osorio, 2010, 2012a y 2012b) o como la película más contundente y completa del país (Manrique, 2014).

Actualmente, Confesión a Laura sigue siendo un prototipo de calidad cinematográfica. Tanto el guion como la película resaltan por su precisión y delicadeza, "en esta cinta prima la importancia de las palabras, el valor de su sentido que con cuidado se desnuda, se trata de una película de detalles en la que los sentimientos se expresan a través de miradas" (Fonnegra, 2012, p. 33).

En síntesis, nuestra película es una obra que cualquier estudioso 0 amante del cine (tanto de las películas como de los guiones) debe conocer. Alzate (2011) reitera su 
lugar dentro del cine colombiano: "Las Confesión a Laura de nuestro cine acaso se dan una vez por década y, me temo, en total no suman cinco en toda la historia" (cursiva nuestra).

Pese a estas virtudes, la película ha recibido escasa atención por parte de la comunidad académica, situación que se evidencia en las pocas publicaciones que se le han dedicado, enmarcadas globalmente desde la estética (Alba, 2006; Bejarano, 2011; Fonnegra, 2012; Jaramillo, 2010; Ramírez, 2001; Velásquez, 2012). Y según nuestra revisión de antecedentes, no ha sido objeto de estudio pragmalingüístico.

\section{El guion cinematográfico y la película como géneros distintos}

Aunque parezca una obviedad, es importante resaltar que un guion y su película no son géneros textuales equivalentes. Sin embargo, el estatus del guion como obra independiente aún sigue discutiéndose, pues para algunos el guion constituye un texto de transición que sirve solamente como indicación para la filmación. Esta postura se viene cuestionando desde hace un par de décadas, pues se plantea que el guion es un texto autónomo de un género específico (para una revisión, ver Pollarolo, 2011 y Ríos, 2008).

Así, dada su utilización instrumental y sus semejanzas con el texto teatral, el guion ha sufrido un menosprecio reiterado. Si bien la pragmática cuenta con investigaciones sobre el cine, los antecedentes que diferencien entre guion y película o retomen exclusivamente el primero son escasos (Alba-Juez, 2008; Almeida, Dos Santos \& Rebollo, 2008; Liverani, 2005; Monjour, 2006; Nieto, 2011; 0'Conell, Kowal \& Ping, 2007). Aunque aquí las desarrollaremos, cuestiones como la equiparación entre guion y película, o entre guion y transcripción escrita de la película, exigen una discusión metodológica dentro de la pragmática.

Igualmente, la relación entre guion y texto teatral amerita reflexión, pues pese a presentar semejanzas, sus condiciones de producción, interpretación y circulación no son equivalentes.

El guion cinematográfico puede ser descrito como un género literario que toma prestadas características de los dos géneros que se encuentran más próximos a él: la novela y la dramaturgia. La diferencia que observaría el guion cinematográfico con respecto a estos últimos es que no se trata de un género literario constituido a lo largo de siglos, con un sinnúmero de ejemplos, con condiciones establecidas, sino de un género en formación. (Ríos, 2008, p. 103) 
Para diferenciar el género específico, Ríos propone algunas reglas del guion (2008, pp.142-154), partiendo del principio de ajuste a la producción cinematográfica: división por escenas con encabezados de producción claros, descripción del movimiento dramático, cierre de la escena, articulación en los momentos de producción del proyecto y flexibilidad ante la discusión constante durante la filmación, entre otras.

Una última cuestión influye en la escasez de estudios sobre el guion, no solo en pragmática sino en semiótica general: tales documentos son contados en el mercado editorial (Quiroga, 2010). Entre el valor instrumental y el recelo de muchos directores que solo filman lo propio, el ejercicio de análisis del guion es difícil, de allí la relevancia de publicaciones como el guion de Confesión a Laura (Cardona, 2010).

A efectos de este análisis, consideramos que el guion y la película constituyen ejemplificaciones de prototipos acerca de categorías comunicativas y sociológicas como la conversación cotidiana o el lugar de la mujer en el contexto sociohistórico. Así, podemos establecer que Confesión a Laura nos ilustra sobre los usos del registro coloquial (Briz, 2010) de la Bogotá de mediados de siglo: una sociedad conservadora, rica en estrategias de cortesía negativa, enfocada en el distanciamiento y la jerarquía.

\section{La atenuación pragmática y la conversación coloquial}

En consonancia con la estrategia metodológica empleada, conceptualizamos la atenuación como una categoría pragmática que cumple doble función: minimizar la fuerza ilocutiva de los actos de habla, o reducir (y desfocalizar) el papel de los participantes en la enunciación (Albelda et al., 2014).

De esta manera, la atenuación apunta al acercamiento en términos interpersonales y al distanciamiento en términos informacionales. De aquí que se relacione predominante, aunque no exclusivamente, con la cortesía (para una revisión, ver Albelda, 2010, y Briz \& Albelda, 2013).

Por otro lado, establecemos que Confesión a Laura sucede en el registro de conversación coloquial, definiendo esta última según los siguientes parámetros (Briz, 1998, p. 42; 2006, p. 231):

$$
\begin{aligned}
& \text { + igualdad entre los interlocutores } \\
& \text { + relación de proximidad } \\
& \text { + familiaridad / cotidianidad } \\
& \text { - habla planificada } \\
& \text { + finalidad socializadora }
\end{aligned}
$$




$$
\begin{aligned}
& \text { + tono informal } \\
& + \text { interlocución en presencia } \\
& + \text { inmediatez } \\
& + \text { dinámica }
\end{aligned}
$$

\section{Metodología y materiales}

\subsection{Diseño metodológico}

El análisis del guion se enmarca en un diseño mixto, no experimental, de alcance descriptivo.

\subsection{Materiales}

En primer lugar, tenemos el guion publicado (Cardona, 2010), que cuenta como corpus original. El texto se divide en 42 secuencias, de las cuales 18 contienen un total de 93 actos de atenuación.

A continuación se filtran todos los actos de atenuación (Grupo Val.Es.Co, 2014) y se transcriben a la ficha se análisis de atenuación planteada por el grupo Val.Es.Co ${ }^{2}$.

La ficha ofrece un factor cualitativo (el fragmento con atenuación) y cinco grandes factores que se puntúan cuantitativamente.

Tabla 1. Bloques de análisis de atenuación

\begin{tabular}{|l|l|}
\hline \multirow{2}{*}{ bbjeto de estudio: los atenuantes } & (A) Función de la atenuación \\
\cline { 2 - 3 } & (B) $\begin{array}{l}\text { Procedimiento lingüístico de atenuación (las tác- } \\
\text { ticas) }\end{array}$ \\
\hline \multirow{2}{*}{$\begin{array}{l}\text { Factores que inciden en el uso de la ate- } \\
\text { nuación }\end{array}$} & (C) Factores enunciativos \\
\cline { 2 - 2 } & (D) Factores estructurales \\
\cline { 2 - 2 } & (E) Factores situacionales \\
\hline
\end{tabular}

Fuente: Grupo Val.Es.Co (2013, p. 5)

Cada uno de los factores se compone de variables específicas. En el caso de (B) atenuación, contamos con 21 identificadas, más una de "otros" (para mecanismos no planteados). La sección 2.1 resalta aquellas más relevantes en el corpus.

2 Materiales disponibles en http://esvaratenuacion.es/material/ 
La ficha fue modificada en los siguientes puntos:

i. Factor 4: Posición discursiva del atenuante: se añadió un séptimo nivel a la variable, equivalente a Aparición inicial y final de distintos atenuadores en un mismo acto atenuante. Nótese que en la ficha de ejemplo ofrecida por el grupo Val.Es.Co, a falta de este nivel, se codifica con los niveles inicial y final juntos (“3_4”) lo cual obstaculiza el análisis estadístico. (Ver sección 2.2).

ii. Factor 8: Temática: se añadió un quinto nivel a la variable, sin definición establecida, pero que corresponde a aquellos temas que, en el cariz particular de Confesión a Laura, no son propiamente cotidianos (no en el sentido ofrecido por Grupo Val.Es.Co, 2013), pero tampoco los excluyen. (Ver sección 2.3).

iii. Análisis cualitativo: dado que se cuenta con parámetros pragmáticos en las didascalias del guion, se optó por sintetizar las secuencias en las que se divide Confesión a Laura y que contextualizan las emisiones. Según nuestro criterio, basta con la articulación entre ambos elementos para comprender la progresión de la trama.

\subsection{Procedimientos de análisis de la información}

La base de datos fue codificada y analizada en el programa SPSS versión 23. Solo se corrieron estadísticos descriptivos.

\section{Resultados}

En principio, baste anunciar que se identificaron 93 actos de atenuación en el guion. De la película, se identificaron cuatro actos que no aparecen en este. De los presentes en el guion, cinco no fueron representados por los actores en la película.

\subsection{Atenuación en el guion}

A continuación presentaremos los descriptivos del guion, focalizándonos en la función y procedimientos de la atenuación. Solo resaltaremos los procedimientos más relevantes según la frecuencia de aparición y su preponderancia pragmática en el intercambio comunicativo. 


\subsubsection{Función general del atenuante}

Tabla 1. Frecuencias de Función general del atenuante

\begin{tabular}{|l|l|l|l|}
\hline \multicolumn{2}{|c|}{ 1. Función general del atenuante } & Frecuencia & \multicolumn{1}{c|}{ Porcentaje } \\
\hline \multirow{4}{*}{ Válido } & Autoprotegerse sin imagen & 15 & 16,1 \\
\cline { 2 - 4 } & Autoprotegerse con imagen & 21 & 22,6 \\
\cline { 2 - 4 } & Prevenir daño a imagen 0 & 39 & 41,9 \\
\cline { 2 - 4 } & Reparar daño a imagen 0 & 18 & 19,4 \\
\cline { 2 - 4 } & Total & 93 & 100,0 \\
\hline
\end{tabular}

La mayoría de las intervenciones apuntan a la imagen del oyente. En efecto, dada la naturaleza del contexto sociohistórico, encontramos tanto estrategias convencionalizadas (1) como emisiones especificadas en construcciones más extensas (2):

(1) LAURA

\section{Don Santiago... Don Santiago...}

(SANTIAGo reacciona, la mira).

Que por favor pase al teléfono. (p. 36) ${ }^{3}$

(2) Josefina

Si yo fuera usted lo haría... (Se acerca un poco más a SANTIAGo) De todas maneras eso es problema suyo, usted verá. (Suaviza el tono) Yo venía a decirle otra cosa, es que necesito que vaya un momento donde Laurita. (pp. 28-29)

Los ejemplos anteriores ilustran la función de protección de la imagen del 0 previa a su amenaza. La reparación también presenta realizaciones breves (3) y elaboradas (4):

(3) Josefina

(Se asoma al marco de la puerta de la cocina) Bájele un poquito, ¿sí? (p. 26)

(4) Santiago

3 Las convenciones de transcripción se toman de Grupo Val.Es.Co (2013). 
[...] Por eso en mi casa jamás, ni por error, nos tomaremos una infusión que no sea de yerbas frescas, ieso nunca!

(Mientras dice esto encuentra el toronjil. Está en un manojo de hierbas completamente secas. Se avergüenza. Mira apenado a Laura. Esta baja la cabeza).

SANTIAGO

(Mirando el manojo de hierbas secas) Bueno claro que... eso no es exactamente cierto... la verdad, en una ocasión nosotros... Josefina...

(LauRA lo mira de reojo, apenada). (pp. 48-49)

\subsubsection{Movimiento de reformulación}

Constituye el procedimiento de mayor aparición y, junto con las elipsis (2.1.3) y justificaciones (2.1.4), ejemplifica el estilo conversacional característico de la obra: la discusión de cuestiones polémicas, íntimas o incómodas lleva a los hablantes a replantear, interrumpir 0 justificar lo dicho.

Tabla 2. Frecuencias de Movimiento de reformulación

\begin{tabular}{|l|l|l|l|}
\hline \multicolumn{2}{|c|}{$\mathbf{2 . 1 6}^{*}$ Reformulación } & Frecuencia & Porcentaje \\
\hline \multirow{4}{*}{ Válido } & No reform. & 53 & 57,0 \\
\cline { 2 - 4 } & Reform. partícula & 31 & 33,3 \\
\cline { 2 - 4 } & Reform. no partíc. & 4 & 4,3 \\
\cline { 2 - 4 } & Cambio de tópico & 5 & 5,4 \\
\cline { 2 - 4 } & Total & 93 & 100,0 \\
\hline
\end{tabular}

"Nota: la numeración (2.16) corresponde al código de la ficha Val.Es.Co (2013).

La mayoría de las reformulaciones depende de partículas en posición inicial, a modo de marcadores discursivos que anuncian el cambio de contenido ilocucionario, como en (4) y (5) o contenido informacional (6).

(5) LaURA

(Indecisa) ... a Josefina no le gusta recibir así de improviso...

SANTIAGO 
¿Pero qué dice, si no se trata de una visita de cortesía, es una emergencia!

LAURA

(Recuperando un poco la serenidad) De pronto sí, tiene razón... se lo agradezco, mejor me voy con usted. (p. 42).

(6) LAURA

(Nerviosa) ¿Cómo está?... gracias a Dios... Sí, yo estoy bien. Don Santiago es el que sigue un poco aturdido, pero está bien... (p. 35)

En el último ejemplo, la referencia de Laura acerca del estado de Santiago se ve matizada por la preposición adversativa pero, que le permite replantear la descripción previa.

\subsubsection{Elipsis de la conclusión, estructuras suspendidas o estructuras truncadas}

Tanto en el guion como en la película, los hablantes suelen dejar abiertos sus enunciados, en una frecuencia relevante, como se presenta abajo. Ya muy temprano se emplea este recurso para dar cuenta de uno de los tópicos problemáticos: el Bogotazo (7).

Tabla 3. Frecuencias de Elipsis

\begin{tabular}{|l|l|l|l|}
\hline \multicolumn{2}{|c|}{ 2.13 Elipsis } & Frecuencia & Porcentaje \\
\hline \multirow{3}{*}{ Válido } & No elipsis & 66 & 71,0 \\
\cline { 2 - 4 } & Elipsis & 27 & 29,0 \\
\cline { 2 - 4 } & Total & 93 & 100,0 \\
\hline
\end{tabular}

(7) Josefina

\section{¿Y lo del desayuno?}

SANTIAG0

Es imposible, Josefina, no bay nada abierto. Fui basta la veinticinco y eso es una locura usted no...

JOSEFINA 


\section{(Interrumpe) ¿Pero cómo? (Contrariada) ¿Entonces no consiguió nada?}

SANTIAGO

Pero si usted viera cómo están las calles, lo de ayer fue terrible, los almacenes parecen, (pausa) no sé..., (preocupado) es una cosa espantosa. (p. 24)

Nos permitimos presentar (7) con un contexto previo amplio dada su representatividad: es el primer acto de atenuación en el corpus. La elipsis da cuenta tanto del estado psicológico del $\mathrm{H}$, en su afectación por la tragedia acaecida, como de la incapacidad de describir con detalle la situación que, en último término, le permitiría justificar no haber cumplido con su compromiso de traer víveres.

La relevancia de la reformulación se reitera en el núcleo de la "confesión”, en la bellísima secuencia 37 del guion, que presentamos en los ejemplos (8) y (9), donde tanto Santiago como Laura reconocen que han mentido acerca de lo que dijeron ser y no ser, reconociendo sus debilidades y ansias. Luego de esta secuencia, la trama dará paso a su cierre y no mostrarán más atenuaciones ni en guion ni película.

(8) Santiago

$Y$ usted me dice, porque lo nota..., ¿Qué piensa?... no qué piensa Josefina... "¿Qué piensa usted?”. iAb!... eso me dijo iverdad? (LauRA asiente) ¿Y qué?... ¿Fui capaz de responderle? No. Porque yo, yo..., soy un... un..., porque a mí me da miedo siquiera permitirme sentir lo que siento, decir del librito ese que tiene abi (señala la biblioteca) ese... idecir que sí creía en Gaitán! (p. 100)

(9) LaURA

Pero si no es muy difícil... todos piensan lo mismo y la verdad, no se equivocan. (Con mucha tristeza) Porque yo sí soy como ellos se imaginan. No como quise ser... soy... es lo mismo..., (indecisa) a mi me babría gustado... tener... no sé... con alguien... ¿Se da cuenta?... yo no soy... quería... pero (lo mira con los ojos llenos de lágrimas) usted sabe... yo ... (pp. 100-101)

(8) y (9) ilustran la difícil precisión asertiva que, acerca de sí mismos, pueden lograr los hablantes. 


\subsubsection{Partículas y construcciones justificadoras o de excusa}

Reconocemos dos factores que propician el recurso a justificaciones. En primer lugar, la amenaza a la imagen de hablante y oyente. En segundo lugar, la atmósfera de "formalismo coloquial": distanciamiento y jerarquía, pese a tratarse de relaciones interpersonales cercanas (esposos, conocidos, amigos, amantes).

(10) JosEFina

(Lo interrumpe) Usted tiene la obligación de serle fiel al Gobierno y mucho más en estos momentos cuando, si es verdad lo que dice, hay tanto peligro... hasta debería presentarse hoy al Ministerio a ver qué se ofrece.

SANTIAGO

(Atemorizado) iCómo se le ocurre!

Joserina

Si yo fuera usted lo haría... (Se acerca un poco más a SANTIAGo) De todas maneras eso es problema suyo, usted verá. (p. 29)

(11) LAURA

iUf!, creo que ya no puedo más... (Se mira los pies) Perdone, Don Santiago, pero creo que me tengo que quitar estos zapatos, iya no los aguanto!... (p. 63)

Estos actos ilustran sendas justificaciones focalizadas en la imagen: del oyente (10), nótese que Josefina (10) plantea una emisión que le da cierta libertad de acción a su esposo manteniendo su jerarquía superior; y del hablante (11), donde Laura busca establecer la aceptabilidad de una acción poco recomendable dado el distanciamiento (y que se apoya con la intensificación final).

Para terminar, retomemos el acto (4), que conjuga los tres mecanismos más relevantes: reformulación, elipsis y justificación:

\section{(4) Santiago}

[...] Por eso en mi casa jamás, ni por error, nos tomaremos una infusión que no sea de yerbas frescas, ieso nunca! 
(Mientras dice esto encuentra el toronjil. Está en un manojo de hierbas completamente secas. Se avergüenza. Mira apenado a Laura. Esta baja la cabeZa).

SANTIAG0

(Mirando el manojo de hierbas secas) Bueno claro que... eso no es exactamente cierto... la verdad, en una ocasión nosotros... Josefina...

(LAura lo mira de reojo, apenada). (pp. 48-49)

\subsubsection{Otros procedimientos}

En primer lugar, las peticiones, preguntas, mandatos $u$ órdenes expresados de forma indirecta aparecen atenuados con una frecuencia elevada, superior incluso a las elipsis, aunque sin la misma relevancia en momentos claves del drama, razón por la cual las presentamos en este apartado:

Tabla 4. Frecuencia de Peticiones, preguntas, mandatos u órdenes expresados de forma indirecta

\begin{tabular}{|l|l|l|l|}
\hline \multicolumn{2}{|c|}{ 2.9 Peticiones indirectas } & Frecuencia & Porcentaje \\
\hline \multirow{4}{*}{ Válido } & No petición indirecta & 64 & 68,8 \\
\cline { 2 - 4 } & Pet. indirecta afirmación & 16 & 17,2 \\
\cline { 2 - 4 } & Pet. indirecta negación & 6 & 6,5 \\
\cline { 2 - 4 } & 'Por favor' & 7 & 7,5 \\
\cline { 2 - 4 } & Total & 93 & 100,0 \\
\hline
\end{tabular}

(2) JosEFina

Si yo fuera usted lo baría... (Se acerca un poco más a SANTIAGo) De todas maneras eso es problema suyo, usted verá. (Suaviza el tono) Yo venía a decirle otra cosa, es que necesito que vaya un momento donde Laurita. (pp. 28-29)

(12) LAURA

Si quiere leer algo, bien pueda. (p. 74)

(13) SANTIAGO 
(Continúa observando. se detiene en algo que le llama la atención, está abajo, se agacha. va a tocarlo. se detiene. le dice a Laura).

SANTIAG0

\section{¿Puedo? (p. 74)}

Así, la mayoría de actos de habla directivos se apoya en la indirección, apareciendo como una marca que reitera el énfasis en la cortesía negativa y los parámetros de relación social de la época.

Las formas de tratamiento también tienen una frecuencia importante, aparecen en casi todas las emisiones junto con otros procedimientos:

(1) LAURA

\section{Don Santiago... Don Santiago...}

(SANTIAGo reacciona; la mira).

Que por favor pase al teléfono. (p. 36)

(14) LaURA

Eso es peligroso. No. Tenemos que buscar algo que se pueda poner mientras le seca el pantalón... (Pausa. Pensativa) ¿Pero qué?... (Lo mira. Dice resuelta) No hay más remedio, Don Santiago, le va a tocar ponerse una falda. (p. 65)

Tabla 5. Frecuencia de Formas de tratamiento/apelación

\begin{tabular}{|l|l|l|l|}
\hline \multicolumn{2}{|c|}{ 2.20 Formas de tratamiento /apelación } & Frecuencia & Porcentaje \\
\hline \multirow{4}{*}{ Válido } & No F.tratam/apelac & 67 & 72,0 \\
\cline { 2 - 5 } & F. tratamiento & 22 & 23,7 \\
\cline { 2 - 4 } & F. apelativas & 4 & 4,3 \\
\cline { 2 - 4 } & Total & 93 & 100,0 \\
\hline
\end{tabular}

Finalmente, resaltamos cómo dentro del mantenimiento de las buenas relaciones y las argumentaciones/justificaciones, aparecen también procedimientos de concesividad:

(7) Joserina 


\section{¿Y lo del desayuno?}

SANTIAGO

Es imposible, Josefina, no hay nada abierto. Fui hasta la veinticinco y eso es una locura usted no...

JOSEFINA nada?

(Interrumpe) ¿Pero cómo? (Contrariada) ¿Entonces no consiguió

SANTIAGO

Pero si usted viera cómo están las calles, lo de ayer fue terrible, los almacenes parecen, (pausa) no sé..., (preocupado) es una cosa espantosa. (p. 24)

(15) LAURA

(Se dirige a la radiola, mientras le dice a Savtiago) Don Santiago, ¿podría (vacilante) seguir cantando?

SANTIAGO

Bueno... si usted quiere, pero no lo hago muy bien. (p. 79)

Tabla 6. Frecuencia de Concesividad

\begin{tabular}{|l|l|l|l|}
\hline \multicolumn{2}{|c|}{2.17 Concesividad } & Frecuencia & Porcentaje \\
\hline \multirow{3}{*}{ Válido } & No conces. & 70 & 75,3 \\
\cline { 2 - 4 } & Mov. conces. & 17 & 18,3 \\
\cline { 2 - 4 } & Part. disc. conces. & 6 & 6,5 \\
\cline { 2 - 4 } & Total & 93 & 100,0 \\
\hline
\end{tabular}

\subsection{Posición textual}

Como adelantábamos en la sección de Metodología, se planteó un séptimo nivel para facilitar el análisis estadístico, correspondiente a la Aparición inicial y final de distintos atenuadores en un mismo acto atenuante. 
Tabla 7. Frecuencia de Posición textual

\begin{tabular}{|l|l|l|l|}
\hline \multicolumn{2}{|c|}{ 4 Posición textual } & Frecuencia & Porcentaje \\
\hline \multirow{5}{*}{ Válido } & Interm. paréntesis & 8 & 8,6 \\
\cline { 2 - 4 } & Interm. reform. & 6 & 6,5 \\
\cline { 2 - 4 } & Anterior & 10 & 10,8 \\
\cline { 2 - 4 } & Posterior & 15 & 16,1 \\
\cline { 2 - 4 } & Varias posic. & 1 & 1,1 \\
\cline { 2 - 4 } & Acto completo & 45 & 48,4 \\
\cline { 2 - 4 } & Inicial/final varios aten. & 8 & 8,6 \\
\cline { 2 - 4 } & Total & 93 & 100,0 \\
\hline
\end{tabular}

Así, en (7), el contenido atenuado acerca de los almacenes (donde Santiago debía comprar víveres) se ve precedido y sucedido por concesión y elipsis, respectivamente.

(7) JosEFina

\section{¿Y lo del desayuno?}

SANTIAGO

Es imposible, Josefina, no hay nada abierto. Fui hasta la veinticinco y eso es una locura usted no...

JOSEFINA nada?

(Interrumpe) ¿Pero cómo? (Contrariada) ¿Entonces no consiguió

SANTIAG0

Pero si usted viera cómo están las calles, lo de ayer fue terrible, los almacenes parecen, (pausa) no sé..., (preocupado) es una cosa espantosa. (p. 24)

Mientras que en el siguiente, la pregunta referida a la valoración de Santiago acerca de los gaitanistas se enmarca en una fórmula de tratamiento y un eufemismo, necesarias dada la tensión política del momento.

\section{(16) LAURA}

Don Santiago, entonces usted piensa ... ‥ $\underline{\text { así? }}$ (p. 40) 


\subsection{Temática}

La segunda variable a la que se le añadió un nivel fue la temática, esencialmente debido al carácter particular del texto, pues Confesión a Laura se caracteriza por el desvelamiento progresivo de aspectos íntimos que se mantenían ocultos. De esta manera, las definiciones ofrecidas por la guía de la ficha (Grupo Val.Es.Co, 2013, p. 31) resultaban insuficientes: ni el tema Cotidiano ("diario y común en la realización socializadora de la gente") ni el tema No cotidiano, ni especializado, ni ritualizado, nos resultaron adecuados a la sutileza del texto.

Puesto que hay cuestiones que no se discuten en la cotidianidad del contexto, pero siguen siendo asuntos que una vez desvelados pueden tratarse, ni la inclusión en Cotidiano ni la exclusión de esta en No cotidiano, etc. aparecen como suficientes.

Por ahora, consideramos que esta cuestión amerita una discusión más amplia, pues a diferencia de la modificación anterior, parece que se plantea una temática ad hoc. Véase, empero:

(8) Santiago

$Y$ usted me dice, porque lo nota..., ¿Qué piensa?... no qué piensa Josefina... "¿Qué piensa usted?”. iAh!... eso me dijo iverdad? (LauRA asiente) ¿Y qué?... ¿ ¿Fui capaz de responderle? No. Porque yo, yo..., soy un... un.... porque a mí me da miedo siquiera permitirme sentir lo que siento, decir del librito ese que tiene ahi (señala la biblioteca) ese... idecir que sí creía en Gaitán! (p. 100)

(9) LauRA

Pero si no es muy difícil... todos piensan lo mismo y la verdad, no se equivocan. (Con mucha tristeza) porque yo sí soy como ellos se imaginan. No como quise ser... soy... es lo mismo..., (Indecisa) a mí me habría gusta$d o . .$. tener... no sé... con alguien... ¿Se da cuenta?... yo no soy... quería... pero (lo mira con los ojos llenos de lágrimas) usted sabe... yo ... (pp. 100-101) 
Tabla 8. Frecuencia de Temática

\begin{tabular}{|l|l|l|l|}
\hline \multicolumn{2}{|l|}{ 8 Temática } & Frecuencia & Porcentaje \\
\hline \multirow{3}{*}{ Válido } & 0 & 73 & 78,5 \\
\cline { 2 - 4 } & 4 & 20 & 21,5 \\
\cline { 2 - 4 } & Total & 93 & 100,0 \\
\hline
\end{tabular}

Sin embargo, esta impresión se basa en valoraciones estéticas, no pragmáticas, por lo que la enunciamos como una posibilidad para desarrollar posteriormente.

\section{Conclusiones}

De manera consecuente con la impresión informal y estética, Confesión a Laura es un texto rico en mecanismos de atenuación. Encontramos que predominan, tanto en frecuencia como en relevancia retórica, los mecanismos de Reformulación, Elipsis y Justificación. En segundo lugar de relevancia y frecuencias están los mecanismos de Peticiones etc. expresados de forma indirecta, Formas de tratamiento/apelación y Concesividad.

La anexión de un séptimo nivel de Posición discursiva puede resultar útil en distintos análisis que empleen la ficha metodológica. Por otro lado, las modificaciones de Temática y Análisis cualitativo deben evaluarse y discutirse a la luz de análisis más profundos y con mayor número de corpus.

La ficha metodológica de análisis de atenuación ofrecida por el Grupo Val.Es.Co es una herramienta que permite estudiar la conversación en textos ficticios, como guiones y, potencialmente, en otros textos literarios. Queda también como tarea posterior confirmar esta extensión.

Hay otros aspectos de la ficha que requieren revisión y no se trataron aquí, como el lugar de origen del hablante, que se refiere a un contexto muy específico y puede ampliarse.

\section{Referencias}

Alba, G. (2006). La narración en el largometraje colombiano de ficción 1950-2000. Razón y Palabra, 49, 1-21.

Alba-Juez, L. (2008). Sobre algunas estrategias y marcadores de descortesía en español peninsular y argentinos: ¿Son españoles y argentinos igualmente descorteses? En A. Briz, A. Hidalgo, M. Albelda, M., J. Contreras \& N. Hernández (eds.), Cortesía y conversación: de lo 
escrito a lo oral. III Coloquio Internacional del Programa EDICE (pp. 72-79). Valencia: Universitat de València, Programa EDICE.

Albelda, M. (2010). ¿Cómo se reconoce la atenuación? Una aproximación metodológica basada en el español peninsular hablado. En F. Orletti \& L. Mariottini (eds.), (Des)cortesía en español. Espacios teóricos metodológicos para su estudio (pp. 46-70). Roma: Programa EDICE.

Albelda, M., Briz, A., Cestero, A., Kotwica, D. \& Villalba, C. (2014). Ficha metodológica para el análisis pragmático de la atenuación en corpus discursivos del español (ES.POR. ATENUACIÓN). Oralia, 17, 7-62.

Almeida, F., Dos Santos, C. \& Rebollo, L. (2008). Agradecimientos y disculpas en el cine latinoamericano. Representaciones de Buenos Aires, Bogotá, Ciudad de México, La Habana, Lima, Madrid, Santiago de Chile y Río de Janeiro. En A. Briz, A. Hidalgo, M. Albelda, M., J. Contreras \& N. Hernández (eds.), Cortesía y conversación: de lo escrito a lo oral. III Coloquio Internacional del Programa EDICE (pp. 604-622). Valencia: Universitat de València, Programa EDICE.

Alzate, C. (2011). El cinéfilo. Cronopio, 25. Recuperado de http://www.revistacronopio.com/ $? \mathrm{p}=6680$

Bejarano, A. (2011). Cine y espectro. Presencia de lo fantasmático en Confesión a Laura. Revista La Tadeo, 76, 191-203.

Briz, A. (1998). El español coloquial en la conversación. Esbozo de pragmagramática. Barcelona: Ariel.

Briz, A. (2006). Atenuación y cortesía verbal en la conversación coloquial: su tratamiento en la clase de ELE. En Actas del programa de formación para profesorado de ELE (pp. 227255). Munich: Instituto Cervantes.

Briz, A. (2010). El registro como centro de la variedad situacional. Esbozo de la propuesta del grupo Va.Es.Co sobre las variedades diafásicas. En I. Fonte \& L. Rodríguez (comps.), Perspectivas dialógicas en estudios del lenguaje (pp. 21-56). México, D.F: Universidad Autónoma de Nuevo León.

Briz, A. \& Albelda, M. (2013). Una propuesta teórica y metodológica para el análisis de la atenuación lingüística en español y portugués. La base de un proyecto común (ES.POR. ATENUACIÓN). Onomázein, 28, 288-319.

Cardona, A. (2010). Confesión a Laura -Guion-. Medellín: Fondo Editorial Universidad EAFIT y Corporación Festival de Cine Santa Fe de Antioquia. 
Cardona, A. \& Osorio, J. (1990). Confesión a Laura [Película]. Colombia: Méliès Producciones.

Ceballos, M. (2006). Las pasiones: interacción y retórica. Signo y Pensamiento, 25(49), 170-187.

Fonnegra, P. (2012). Confesión a Laura: entre violencia, máscaras y sueños. Katharsis, 14, 3147.

Grupo Val.Es.Co. (2013). Propuesta de ficha para el análisis pragmático de la atenuación en Ameresco. Recuperado de https://drive.google.com/file/d/0B-DidT7qM4rWnZJWDhyTjNTRzA/view

Grupo Val.Es.Co. (2014). Las unidades del discurso oral. La propuesta Val.Es.Co de segmentación de la conversación (coloquial). Estudios de Lingüística del Español, 35, 13-73.

Haverkate, H. (2002). Los diálogos de Don Quijote de la Mancha: análisis pragmalingüístico en el marco de las máximas griceanas, la teoría de los actos de habla y la teoría de la cortesía. Lingüistica y Literatura, 23(41/42), 11-38.

Jaramillo, A. (2010). ¿Sujeto o simulacro? Conjunción de cuerpo, espacio y alteridad en Oriana de Fina Torres y Confesión a Laura de Jaime Osorio Gómez. Palimpsesvs, 7, 55-62.

Liverani, E. (2005). Los lunes al sol: apuntes para un análisis pragmalingüístico. En L. Blini, M. Calvi \& A. Cancellier (eds.), Actas del XXIII Congreso de la Associazione Ispanisti Italiani. Università di Palermo e Instituto Cervantes.

Manrique, J. (2014). Confesión a Laura, Jaime Osorio. Arcadia, 100. Recuperado de http:// www.revistaarcadia.com/impresa/especial-arcadia-100/articulo/confesion-a-laura-jaimeosorio/35095

Monjour, A. (2006). Más allá de las fronteras de la cortesía: intensificadores interdictos en el cine contemporáneo. Revista Electrónica de Lingüística Aplicada, 5, 71-86.

Nieto, R. (2011). The Role of Conversation Maxims, Implicature and Presupposition in the Creation of Humor: An Analysis of Woody Allen's Anything Else. (Trabajo de grado de maestría no publicado). UCM: Department of English Philology.

0'Conell, D.; Kowal, S. \& King, S. (2007). Interjections in Literary Readings and Artistic Performance. Pragmatics, 17(3), 417-438.

Osorio, 0. (2010). Realidad y cine colombiano, 1990-2009. Medellín: Editorial Universidad de Antioquia.

Osorio, 0. (2012a). Amor y erotismo en el cine colombiano. Un intento de sonrisa que termina en mueca. Universo Centro, 38. Recuperado de http://www.universocentro.com/ NUMER038/Amoryerotismo.aspx 
Osorio, 0. (2012b). 10 personajes inolvidables del cine colombiano. Kinetoscopio, 100.

Pollarolo, G. (2011). El guion cinematográfico, itexto literario? Lexis, 35(1), 289-318.

Quiroga, A. (2010). El drama de los guionistas. En A. Cardona, Confesión a Laura -Guión-. Medellín: Fondo Editorial Universidad EAFIT y Corporación Festival de Cine Santa Fe de Antioquia.

Ramírez, C. (2001). Un trozo de vida rescatado entre las ruinas del 9 de abril: Confesión a Laura. Cuadernos de Filosofía Latinoamericana, 82-85, 299-308.

Ríos, M. (2008). La escritura del presente: el guion cinematográfico como género literario. En Concurso de Ensayo en Humanidades Contemporáneas, (pp. 61-169), De la agresión a las palabras: Segundo Concurso de Ensayo en Humanidades Contemporáneas. Santiago: Universidad Diego Portales.

Vallejo, V. (2012). Un marco metodológico para la investigación pragmalingüística del texto dramático: análisis de Diatriba de amor contra un hombre sentado de Gabriel García Márquez. Lingüística y Literatura, 33(62), 191-210.

Velásquez, M. (2012). En el film colombiano Confesión a Laura, ¿Cuál es la relación existente entre discurso, lazo social y la morfología urbana. (Trabajo de grado no publicado). Maestría en Comunicación, Universidad del Norte, Barranquilla.

Villalba, C. (2015). La ficha ES.VAR.ATENUACIÓN. ¿Un recurso adaptable a todos los géneros? El caso de los juicios orales. Textos en Proceso, 1(2), 1-24. 



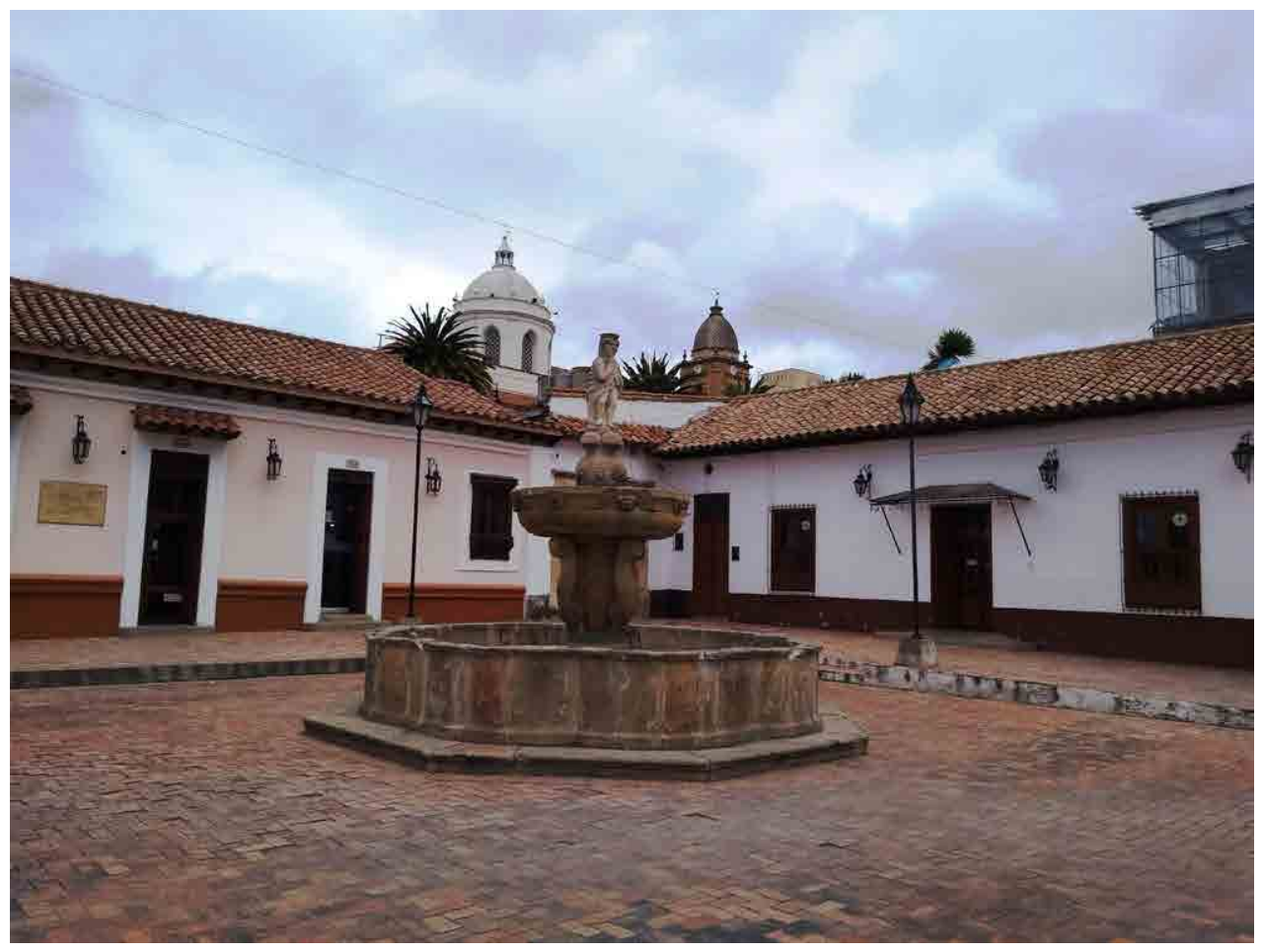

La Pila del Mono, Tunja, Boyacá

\section{PEDAGOGÍA DEL LENGUAJE PEDAGOGY OF LANGUAGE PÉDAGOGIE DU LANGUAGE PEDAGOGIA DA LINGUAGEM}


